\title{
Encefalitis por herpes simple tipo 1 en paciente con trasplante renal
}

\section{Herpes simplex virus-1 encephalitis in a kidney transplant patient}

\author{
Jessica Pinto-Ramirez, Nasly Gisell Patiño-Jaramillo, Andrea Elena García-López, \\ Fernando Girón-Luque • Bogotá, D.C. (Colombia)
}

DOI: https://doi.org/10.36104/amc.2020.1387

\section{Resumen}

La infección por herpes simple tipo 1 (HSV tipo 1) en los pacientes con trasplante renal tiene una incidencia de $3 \%$ en quienes han recibido profilaxis antiviral versus $9.8 \%$ sin profilaxis. Los virus herpes habitualmente producen lesiones mucocutáneas y sólo en ocasiones causan patología visceral o infección del sistema nervioso central en pacientes inmunosuprimidos e inmunocompetentes. La prueba de oro estándar para su diagnóstico es la detección del ADN mediante la reacción de cadena polimerasa (PCR) en el órgano afectado. El tratamiento de acuerdo con la literatura es con aciclovir, con el cual se espera una remisión de la enfermedad en la mayoría de los casos sin secuelas. A continuación, presentamos el caso clínico de un paciente con trasplante renal quien cursó con encefalitis por HSV tipo 1 detectado en líquido cefalorraquídeo (LCR) mediante PCR, quien recibió tratamiento estándar con recuperación completa de su estado neurológico. (Acta Med Colomb 2020; 45. DOI: https://doi.org/10.36104/amc.2020.1387).

Palabras clave: trasplante de riñón, encefalitis por herpes simple, profilaxis antibiótica

\section{Abstract}

The incidence of herpes simplex virus-1 (HSV-1) infection in kidney transplant patients is $3 \%$ in those who have received antiviral prophylaxis versus $9.8 \%$ without prophylaxis. Herpes viruses usually cause mucocutaneous lesions and only occasionally cause visceral disease or central nervous system infection in immunosuppressed and immunocompetent patients. The gold standard for diagnosis is DNA detection using polymerase chain reaction (PCR) in the affected organ. According to the literature, it is treated with acyclovir, with which remission is expected in most cases without sequelae. Here we present the clinical case of a kidney transplant patient who had HSV-1 encephalitis (with the virus detected in the cerebrospinal fluid (CSF) through PCR), and received the standard treatment with complete recovery of his neurological state. (Acta Med Colomb 2020; 45. DOI: https://doi.org/10.36104/amc.2020.1387).

Key words: kidney transplant, herpes simplex encephalitis, antibiotic prophylaxis.
Dra. Jessica Pinto-Ramírez: Nefróloga; Dra. Nasly Gisell Patiño-Jaramillo: Fellow de Investigación; Dra. Andrea Elena García-López: Epidemióloga Clínica; Fernando Girón-Luque: Cirujano de Trasplantes, Líder del Grupo de Investigación. Grupo de Investigación Colombiana de Trasplantes.

Correspondencia: Dra. Jessica Pinto-Ramírez, Bogotá, D.C. (Colombia).

E-mail:jpinto@colombianadetrasplantes.com Recibido: 16/VI/2019Aceptado: 11/II/2020

\section{Introducción}

Las infecciones son la segunda causa de muerte en los pacientes con trasplante de órgano sólido en los tres primeros años (1). La incidencia varía de 3-50 de cada 100 pacientes dependiendo de la profilaxis antiviral (1-3). La infección por HSV tipo 1 es debida en su mayoría a la reactivación del virus, el cual se replica en las mucosas oral y genital, es transportado a ganglios regionales donde establece latencia y raramente se presenta por transmisión del donante a receptor $(2,4,5)$. Una de las razones asociadas a la reactivación del HSV tipo 1 en los pacientes trasplantados, es el manejo con micofenolato mofetil, muromonab CD3 (OKT3), alemtuzumab o medicamentos con una importante depleción en las células T (4).

Las manifestaciones clínicas de la infección por HSV tipo 1 en general son el compromiso mucocutáneo, herpes labial; el compromiso visceral, en forma de hepatitis, esofagitis, neumonía, ceguera corneal, herpes neonatal y mucho menos frecuente la encefalitis, en el cual los pacientes pueden debutar con síndrome convulsivo, fiebre, cefalea, afasia, letargia, confusión y déficit focal que refleja la inflamación en el lóbulo temporal y la superficie orbital de lóbulo fron- 
tal y los pacientes pueden quedar con trastorno convulsivo permanente, alteración de la consciencia o déficit motor $(2$, $3,6,7)$. En un $10 \%$, los pacientes pueden presentar síntomas gastrointestinales y un deterioro del estado mental (5).

Para su diagnóstico neurológico, se cuenta con el estudio de líquido cefalorraquídeo, electroencefalograma (EEG) y neuroimágenes. En el primero, se puede encontrar aumento en la presión de apertura, en el conteo de células en más de 90\% de los pacientes; la pleocitosis típicamente es de predominio mononuclear con una media de 200 células $/ \mathrm{mm}^{3}$, aunque su ausencia no descarta el diagnóstico; aumento en número de proteínas y la glucosa suele ser normal y en el cultivo del líquido raramente aísla el virus, la prueba de oro estándar es la detección del ADN del HSV tipo I por PCR en el LCR $(2,4,7)$. El EEG en pacientes con HSV muestra en algunos complejos de onda aguda y onda lenta (2).

En la tomografía axial computarizada (TAC) se pueden apreciar lesiones hipodensas en regiones temporales mediales y ganglios basales, edema y efecto de masa en $80 \%$ de los casos. En la resonancia magnética (RNM) se revela una disminución de señal en T1 y un aumento de señal en T2 orbitofrontal y lóbulos temporales mediales (2).

El manejo recomendado es con aciclovir IV $10 \mathrm{mg} / \mathrm{kg}$ cada ocho horas por 21 días en pacientes adultos (4). En casos de resistencia al aciclovir puede tratarse con foscarnet, otro tipo de terapias aún se encuentran en investigación (4).

\section{Caso clínico}

Hombre de 56 años, procedente de Montería (Córdoba), ganadero, con antecedente de enfermedad renal crónica (ERC) de causa no clara y trasplante renal de donante cadavérico en julio del 2006. El donante, presentó muerte encefálica por trauma cráneoencefálico (TCE), con perfil infeccioso negativo, sin pruebas serológicas para HSV tipo 1 o 2 de acuerdo con la normatividad nacional del 2004 (8).

El esquema de inducción fue con inmunoglobulina de conejo y la inmunosupresión de mantenimiento desde el momento del trasplante con tacrolimus XL $5 \mathrm{mg} / \mathrm{dia}$; alcanzando niveles entre $2.8 \mathrm{ng} / \mathrm{mL}$ (el valor más bajo) y 5.3 (el valor más alto) con sus respectivos ajustes y ácido micofenólico $1440 \mathrm{mg}$ /día (a este medicamento no se le realiza monitorización con niveles en el país). En el año 2014, cursó con rechazo celular agudo IA según los criterios BANFF del 2013 (9), para lo cual recibió manejo con metilprednisolona, y requirió administración de inmunoglobulina de conejo. En agosto de 2016 se documentó nefropatía crónica del injerto.

En septiembre del 2018 ingresa a urgencias por cuadro de diarrea crónica agudizada de una semana evolución con 10 episodios de deposiciones liquidas al día, sin sangre, ni moco, afebril, no emesis. En la revisión por sistemas, refirió pérdida de $4 \mathrm{~kg}$ en el último mes.

$\mathrm{Al}$ examen físico, con mucosa oral seca, palidez generalizada, taquicárdico 123 latidos/minuto, presión arterial (PA) $145 / 85 \mathrm{mmHg}$, temperatura $36.7^{\circ} \mathrm{C}$, IMC de $35.71 \mathrm{Kg} / \mathrm{m}^{2}$, saturación $96 \%$ con fracción inspirada de oxígeno en $21 \%$, abdomen se palpaba el injerto en fosa iliaca derecha, extremidades sin edemas y al examen neurológico alerta, consciente, orientado sin déficit aparente.

Los paraclínicos de ingreso mostraron hemograma sin leucocitosis, anemia normocítica, normocrómica, potasio normal, creatinina de $3.73 \mathrm{mg} / \mathrm{dL}$ (creatinina basal de $1.6 \mathrm{mg} / \mathrm{dL}$ ).

Durante las primeras 24 horas de estancia presenta episodio convulsivo tonicoclónico con estado pos-ictal prolongado, estupor, Glasgow 9-10 persistente y requiere intubación orotraqueal, benzodiacepinas e inicio de manejo antibiótico de amplio espectro (meropenem y vancomicina), se decide la suspensión de la inmunosupresión dada la severidad del cuadro y manejo en unidad de cuidados intensivos (UCI). En el estado posictal presenta crisis hipertensiva, acidosis metabólica severa, hiperlactatemia, ascenso de creatinina a $6.03 \mathrm{mg} / \mathrm{dL}$, nitrógeno ureico (BUN) $69.6 \mathrm{mg} / \mathrm{dL}$, hemograma con leucocitosis $\left(12320 / \mathrm{mm}^{3}\right)$, linfopenia $(7.8 \%)$ y electrolitos normales. Los hemocultivos, coproscópicos y urocultivo fueron negativos. Se toma radiografía de tórax con cardiomegalia y TAC abdominopélvico sugestivo de íleo. Se estudia carga viral para citomegalovirus (CMV) que es negativa y biopsia renal con glomerulopatía del injerto, sin rechazo. En la TAC de cráneo simple presenta aumento ligero y heterogéneo óseo que podría relacionarse con hiperparatiroidismo. En las posteriores 92 horas, el paciente presenta evolución clínica tórpida permaneciendo en estatus convulsivo a pesar del manejo anticonvulsivante y requiriendo terapia de reemplazo renal continua.

Se consideran como diagnósticos diferenciales sepsis de origen gastrointestinal, neuroinfección, toxicidad por inmunosupresores (a pesar de que los niveles de tacrolimus siempre estuvieron en rangos normales a bajos, en el país no contamos con la medición de nivel de micofenolato en la clínica que pudieran sugerirnos dosis alta del medicamento) y encefalopatía hipóxica versus epilepsia estructural.

Se lleva a cabo RNM cerebral con discreta restricción cortical en la ínsula izquierda y en el tercio posterior del giro del cíngulo ipsilateral (Figura 1), como diagnóstico diferencial se plantea encefalitis autoinmune, con anticuerpos antinucleares, anti-DNA y anticuerpos extractables negativos.

Se realiza punción lumbar (PL) y estudio del LCR en el cual se sospecha encefalitis de etiología viral por presentar hiperproteinorraquia, hiperglucorraquia, pleocitosis (Tabla 1). Se reporta cultivo para micobacterium, cryptococcus y tinta china que junto con adenosín de aminasa (ADA) del LCR son negativos.

Ante la persistencia del deterioro neurológico se realiza EEG en el cual se registra crisis convulsivas y se decide realizar nueva PL con FilmArray de LCR que a las cuatro horas reportó PCR positiva para HSV tipo 1 consolidando el diagnóstico de encefalitis por HSV tipo 1, se inició manejo con aciclovir ajustado a función renal $6 \mathrm{mg} / \mathrm{kg} /$ día para una dosis de $600 \mathrm{mg} /$ día IV por 21 días. A los siete días de tratamiento el paciente presenta mejoría de síntomas neurológicos, se reinicia la inmunosupresión, realiza 
Tabla 1. Examen de LCR obtenido en PL.

\begin{tabular}{|c|c|c|c|}
\hline \multicolumn{4}{|c|}{ Características LCR } \\
\hline Examen físico & Células & Citoquímica & Microbiología \\
\hline \multirow[t]{2}{*}{ Color: amarillo } & Hematíes $843 / \mathrm{mm}^{3}$ & Glucosa: $113 \mathrm{mg} / \mathrm{dL}$ & Mycobacterium tuberculosis: \\
\hline & Frescos :95\% & Referencia adultos: & No detectado \\
\hline \multirow[t]{2}{*}{ Aspecto: ligeramente turbio } & Cremados: $5 \%$ & $40-70 \mathrm{mg} / \mathrm{dL}$ & \\
\hline & Referencia: $0-5 / \mathrm{mm}^{3}$ & & Cryptococcus neoformans: negativo \\
\hline \multirow[t]{3}{*}{ PH: 7} & & Proteínas: $60.3 \mathrm{mg} / \mathrm{dL}$ & \\
\hline & Leucocitos: $4 / \mathrm{mm}^{3}$ & Referencia: $15-45 \mathrm{mg} / \mathrm{dL}$ & Coloración tinta china y lectura: negativo \\
\hline & Referencia adultos: $0-10 / \mathrm{mm}^{3}$ & & \\
\hline
\end{tabular}

rehabilitación multidisciplinaria y a los 21 días de tratamiento egresa del hospital.

En el seguimiento y completadas 12 semanas de haber ocurrido la lesión renal aguda el paciente continúa requiriendo hemodiálisis, no se documentan secuelas neurológicas y se inicia de estudio para retrasplante renal.

\section{Discusión}

La familia de los virus herpes es la responsable de la mayor parte de las infecciones virales en pacientes trasplantados (6).
La incidencia estimada de encefalitis por HSV es de 2-4 casos anuales por millón, siendo el HSV 1 responsable de la mayor parte de dichas encefalitis (6). En la literatura se han reportado 4 casos de encefalitis por HSV tipo 1 (Tabla 2); un paciente con trasplante hepático quien presentó encefalitis por HSV tipo 1 y coinfección con aspergilosis quien fallece (10), los otros tres pacientes remiten tras la terapia con aciclovir, uno de los casos con secuela neurológica $(6,10-12)$.

La profilaxis antiviral en trasplante ha reducido hasta $70 \%$ la incidencia de encefalitis por HSV tipo 1, con el uso de

Tabla 2. Casos reportados en la literatura actual sobre encefalitis por HSV tipo I (6,10-12).

\begin{tabular}{|c|c|c|c|c|c|}
\hline Referencia & Presente & Amenábar et al. & $\mathrm{C}^{\wedge}$ ote-Daigneault et al. & Laohathai et al. & Goméz et al. \\
\hline Género & M & $\mathrm{F}$ & M & M & M \\
\hline Edad & 56 & 47 & 64 & 49 & 36 \\
\hline Número de trasplante & 1 & 1 & 1 & 1 & 3 \\
\hline Trasplante & Renal & Renal & Hepático & Hepático & Renal \\
\hline $\begin{array}{l}\text { Tiempo postrasplante } \\
\text { (Días) }\end{array}$ & 4745 & 90 & 9 & 1460 & 19 \\
\hline Inmunosupresor & $\begin{array}{c}\text { Tacrolimus }+ \text { micofenolato } \\
\text { mofetil }\end{array}$ & $\begin{array}{c}\text { Sirolimus + micofenolato } \\
\text { mofetil + daclizumab }\end{array}$ & Tacrolimus + azatriopina & Ciclosporina & $\begin{array}{c}\text { Ciclosporina }+ \text { azatriopina } \\
\text { Inhibidores OKT3 }\end{array}$ \\
\hline Diagnóstico laboratorio & PCR de LCR & PCR de LCR & PCR de LCR & PCR de LCR & PCR de LCR \\
\hline $\begin{array}{l}\text { Imagenología (RNM } \\
\text { cerebral) }\end{array}$ & $\begin{array}{c}\text { Restricción cortical } \\
\text { ínsula y cíngulo } \\
\text { izquierdo } \\
\text { Engrosamiento }\end{array}$ & $\begin{array}{l}\text { Alta densidad región } \\
\text { frontobasal, insular y } \\
\text { temporal izquierdo }\end{array}$ & Normal & $\begin{array}{l}\text { Edema cortical } \\
\text { temporo-parietal }\end{array}$ & Atrofia cerebral (TAC) \\
\hline $\begin{array}{l}\text { Primario }(\mathbf{P}) \text { o } \\
\text { Reactivación (R) }\end{array}$ & $\mathrm{R}$ & NR & NR & $\mathrm{R}$ & $\mathrm{P}$ \\
\hline $\begin{array}{l}\text { Donante Serología } \\
\text { HSV1 }\end{array}$ & Desconocido & Desconocido & Desconocido & Desconocido & IgG positivo \\
\hline Otros sitios & No & No & Hígado & No & No \\
\hline Aciclovir esquema & $\begin{array}{c}10 \mathrm{mg} / \mathrm{Kg} \text { IV cada ocho } \\
\text { horas } 21 \text { días }\end{array}$ & $\begin{array}{c}10 \mathrm{mg} / \mathrm{Kg} \text { IV cada ocho } \\
\text { horas } 30 \text { días }\end{array}$ & $\begin{array}{l}10 \mathrm{mg} / \mathrm{Kg} \text { IV cada } \\
\text { ocho horas } 21 \text { días }\end{array}$ & $\begin{array}{l}10 \mathrm{mg} / \mathrm{Kg} \text { IV cada } \\
\text { ocho horas } 21 \text { días }\end{array}$ & $\begin{array}{c}\text { Ganciclovir por cuatro } \\
\text { semanas } \\
\end{array}$ \\
\hline Desenlace clínico & Sobrevive & Sobrevive & Murió & Sobrevive & Sobrevive \\
\hline Perdida del injerto & $\mathrm{Si}$ & NR & $\mathrm{Si}$ & No & No \\
\hline Secuela neurológica & No & No & Murió & No & No \\
\hline
\end{tabular}




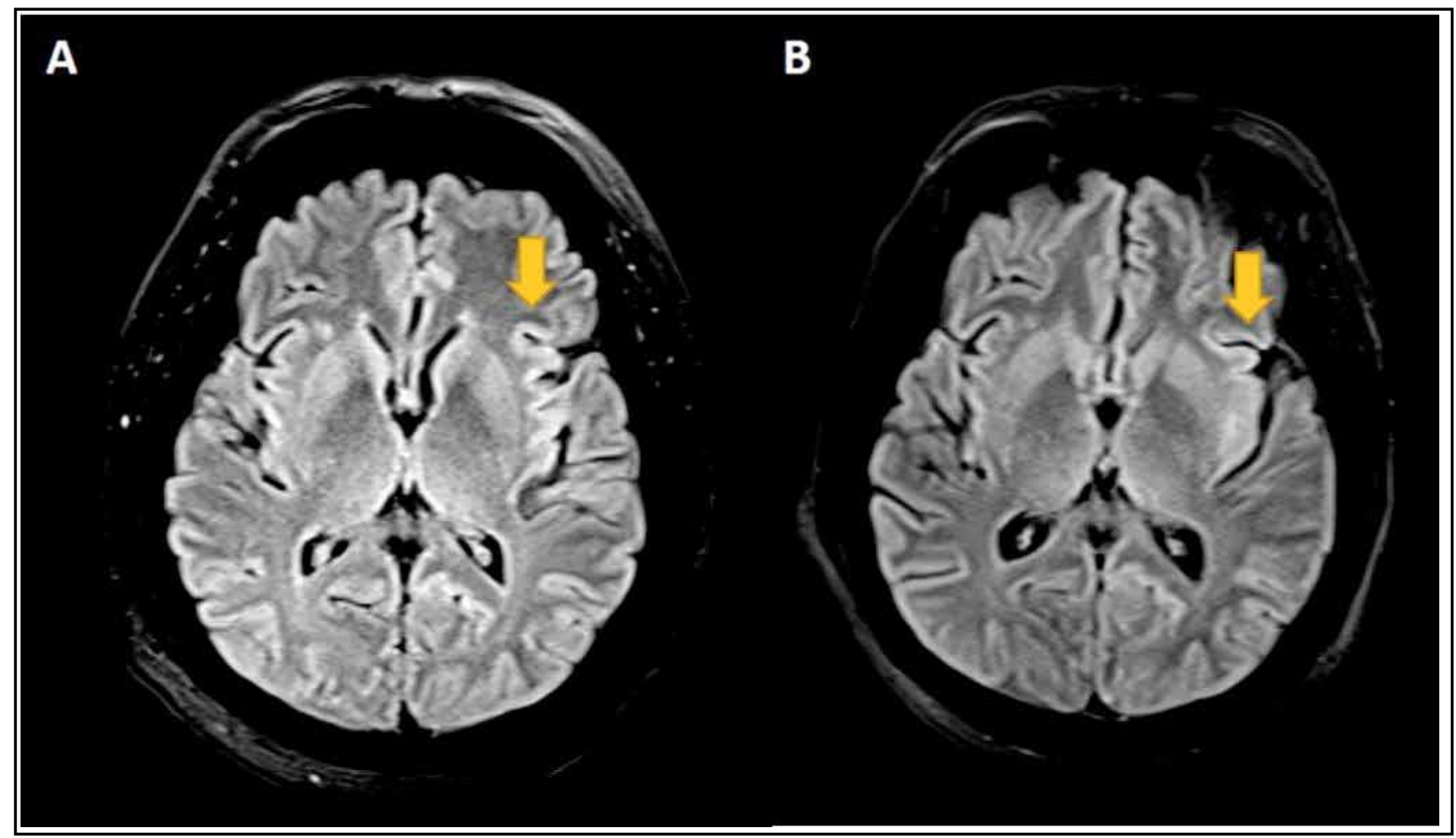

Figura 1. Evolución de lesión insular izquierda en la RNM cerebral. Panel A. Discreta restricción cortical y engrosamiento en la secuencia difusión en la ínsula izquierda y el tercio posterior del giro del cíngulo ipsilateral en la primera RNM cerebral del caso. Panel B. Aumento de la señal en la ínsula izquierda y el tercio posterior del giro del cíngulo ipsilateral con borramiento en el día 4 en RNM cerebral control. Departamento de Imágenes Diagnósticas.

profilaxis con ganciclovir y valganciclovir (5). En un metaanálisis, que incluyó nueve estudios con 1483 pacientes trasplantados la reducción de la incidencia de infecciones por HSV o Herpes zostervirus (HZV) fue significativa con profilaxis con valganciclovir o ganciclovir versus placebo (13). El paciente en discusión recibió profilaxis anti-CMV con valganciclovir por 90 días en el postrasplante inmediato.

Las enfermedades del sistema nervioso central asociadas al virus herpes incluyen encefalitis/ mielitis y desorden linfoproliferativo en el postrasplante (PTLD). El diagnóstico de encefalitis por herpes virus de acuerdo a los criterios internacionales incluyen: 1) signos o síntomas neurológicos; 2) un ADN-virus positivo en LCR; 3) cambios inflamatorios en neuroimágenes; 4) ausencia de otra evidencia etiológica o enfermedades establecidas (14).

Aunque la diarrea por HSV tipo 1 no es frecuente, el micofenolato sí ha sido asociado con cuadros diarreicos persistentes en pacientes con trasplante renal hasta en $38.5 \%$. Los pacientes con este inmunosupresor tienen 1.5 veces mayor riesgo de síntomas gastrointestinales (15).

Los métodos diagnósticos disponibles actualmente son en su mayoría inexactos, exceptuando la PCR en el LCR que detecta el HSV tipo 1 presentando sensibilidad $=100 \%$, especificidad $=99.9 \%$, valor predictivo negativo $(\mathrm{VPN})=$ $100 \%$ y valor predictivo positivo $(\mathrm{VPP})=91.7 \%(2,16,17)$. Exámenes como serologías y cultivos frecuentemente son negativos y pueden no son útiles en el diagnóstico $(6,10)$. Todos los casos consultados, fueron diagnosticados por la detección del virus en la PCR del LCR (5, 10-12).

Un tópico de gran importancia de acuerdo con las guías KDIGO (Kidney Disease: Improving Global Outcomes), en infecciones consideradas graves es reducir o retirar el esquema de inmunosupresión para reducir el riesgo de infección diseminada, aunque esto pueda aumentar las posibilidades de rechazo en el injerto $(18,19)$. En el paciente se aplicó la anterior consideración, sin embargo, no cursó con rechazo, pero tampoco hubo recuperación de la función renal.

A nivel mundial existe una transición epidemiológica de la transmisión del HSV tipo 1, muy bien documentada especialmente en países de occidente; para este fin la Organización Mundial de la Salud, está encabezando esfuerzos para acelerar el desarrollo de vacunas $(3,20)$. La encefalitis por HSV tipo 1 en los pacientes con trasplante renal es una infección viral que debe ser diagnosticada rápidamente e iniciarse el manejo temprano (12). Las limitaciones en el diagnóstico temprano del agente microbiológico pueden generar secuelas neurológicas y compromiso del injerto renal $(4,12,21,22)$.

En resumen, es un caso poco frecuente de encefalitis HSV, a los 12 años de trasplante renal que evolucionó de manera satisfactoria con aciclovir desde el punto de vista neurológico. 


\section{Referencias}

1. Kinnunen S, Karhapää P, Juutilainen A, Finne P, Helanterä I. Secular trends in infection-related mortality after kidney transplantation. Clin J Am Soc Nephrol. 2018;13(5):755-62.

2. Gilden DH, Mahalingam R, Cohrs RJ, Tyler KL. Herpesvirus infections of the nervous system. Nat Clin Pract Neurol [Internet]. 2007 Feb [cited 2019 Apr 29];3(2):82-94. Available from: http://www.nature.com/doifinder/10.1038/ ncpneuro0401

3. Khadr L, Harfouche M, Omori R, Schwarzer G, Chemaitelly H,Abu-Raddad LJ. The epidemiology of herpes simplex virus type 1 in Asia: Systematic review, meta-analyses, and meta-regressions. Clin Infect Dis. 2019 Feb 15;68(5):757-72.

4. Lee DH, Zuckerman RA. AST Infectious Diseases Community of Practice. Herpes simplex virus infections in solid organ transplantation: Guidelines from the American Society of Transplantation Infectious Diseases Community of Practice. Clin Transplant [Internet]. 2019 Apr 11 [cited 2019 Apr 29];e13526. Available from: http://www.ncbi.nlm.nih.gov/pubmed/30859647

5. Netchiporouk E, Tchervenkov J, Paraskevas S, Sasseville D, Billick R. Evaluation of Herpes Simplex Virus Infection Morbidity and Mortality in Pancreas and Kidney-Pancreas Transplant Recipients. Transplant Proc [Internet]. 2013 Nov;45(9):3343-7. Available from: http://www.ncbi.nlm.nih.gov/ pubmed $/ 24182813$

6. Amenábar JJ, Durán MI, Montejo M, Lampreabe I. Encefalitis por virus herpes simple en paciente portadora de trasplante renal. Estudio de un caso y revisión de la literatura. Nefrologia. 2006;26(2):270-3.

7. Wilck MB, Zuckerman RA. AST Infectious Diseases Community of Practice. Herpes Simplex Virus in Solid Organ Transplantation. Am J Transplant [Internet]. 2013 Mar;13(s4):121-7. Available from: http://www.ncbi.nlm.nih.gov/ pubmed/23465005

8. Ministerio de la Protección Social. Decreto 2493 de 2004. 2004;2004(Agosto 4):1-23. Available from: http://www.ins.gov.co/lineas-de-accion/Red-NacionalLaboratorios/Marco Legal/Decreto 2493 del 2004.pdf

9. Haas M, Sis B, Racusen LC, Solez K, Glotz D, Colvin RB, et al. Banff 2013 Meeting Report: Inclusion of C4d-Negative Antibody-Mediated Rejection and Antibody-Associated Arterial Lesions. Am J Transplant [Internet]. 2014 Feb [cited 2020 Jan 30];14(2):272-83. Available from: http://doi.wiley.com/10.1111/ ajt. 12590

10. Côté-Daigneault J, Carrier FM, Toledano K, Wartelle-Bladu C, Willems B. Herpes simplex hepatitis after liver transplantation: case report and literature review. Transpl Infect Dis [Internet]. 2014 Feb [cited 2019 Apr 30];16(1):130-4. Available from: http://www.ncbi.nlm.nih.gov/pubmed/24383552

11. Laohathai C, Weber DJ, Hayat G, Thomas FP. Chronic herpes simplex type-1 encephalitis with intractable epilepsy in an immunosuppressed patient. Infection. 2016;44(1): 121-5.

12. Gómez E, Melón S, Aguado S, Sánchez JE, Portal C, Fernandez A, et al. Herpes simplex virus encephalitis in a renal transplant patient: diagnosis by polymerase chain reaction detection of HSV DNA. Am J Kidney Dis [Internet]. 1997 Sep [cited 2019 May 3];30(3):423-7. Available from: http://www.ncbi.nlm.nih.gov/ pubmed/9292572

13.Hodson EM, Ladhani M, Webster AC, Strippoli GF, Craig JC. Antiviral medications for preventing cytomegalovirus disease in solid organ transplant recipients. Cochrane Database Syst Rev [Internet]. 2013 Feb 28 [cited 2019 May 7];(2):CD003774. Available from: http://www.ncbi.nlm.nih.gov/ pubmed/23450543

14. Aberle SW, Puchhammer-Stöckl E. Diagnosis of herpesvirus infections of the central nervous system. J Clin Virol [Internet]. 2002 Jul [cited 2020 Jan 31];25:79-85. Available from: https://linkinghub.elsevier.com/retrieve/pii/ S1386653202000379

15. Aulagnon F, Scemla A, DeWolf S, Legendre C, Zuber J. Diarrhea after kidney transplantation: A new look at a frequent symptom. Transplantation. 2014;98(8):806-16.

16. Leber A, Everhart K, Demogines A, Fouch S, Barney T, Daly JA, et al. MultiCenter Clinical Evaluation of a Multiplex Meningitis / Encephalitis PCR Panel for Simultaneous Detection of Bacteria , Yeast , and Viruses in Cerebrospinal Fluid Specimens. J Clin Microbiol. 2015;54(9):2251-61.

17. López-Amor L, Escudero D, Fernández J, Martín-Iglesias L, Viña L, Fernández-Suárez J, et al. Diagnóstico de meningitis/encefalitis en UCI con sistema de PCR múltiple. ¿Es tiempo de cambio? Rev Esp Quimioter. 2019;32(3):246-53.

18. Bromberg JS, Fairchild RL, Feng S, Kaplan B, Barr ML, Grady JO, et al. American Journal of Transplantion. Am J Transplant. 2008;8(6): 1084.

19. Sachdeva S, Sulania A, Dwivedi N. Knowledge, Attitude and Practices Regarding Organ Donation among Adult Visitors in a Public Hospital in Delhi , India. Indian J Transplant. 2017; 11(3): 127-132.

20. Gottlieb SL, Giersing B, Boily MC, Chesson H, Looker KJ, Schiffer J, et al. Modelling efforts needed to advance herpes simplex virus (HSV) vaccine development: Key findings from the World Health Organization Consultation on HSV Vaccine Impact Modelling. Vol. 37, Vaccine. Elsevier Ltd; 2019. p. 7336-45.

21. Steiner I, Benninger F. Manifestations of Herpes Virus Infections in the Nervous System. Neurol Clin. 2018;36(4):725-38.

22. Saylor D, Thakur K, Venkatesan A. Acute encephalitis in the immunocompromised individual. Curr Opin Infect Dis [Internet]. 2015;28(4):330-6. Available from: http://www.ncbi.nlm.nih.gov/pubmed/26098507 